
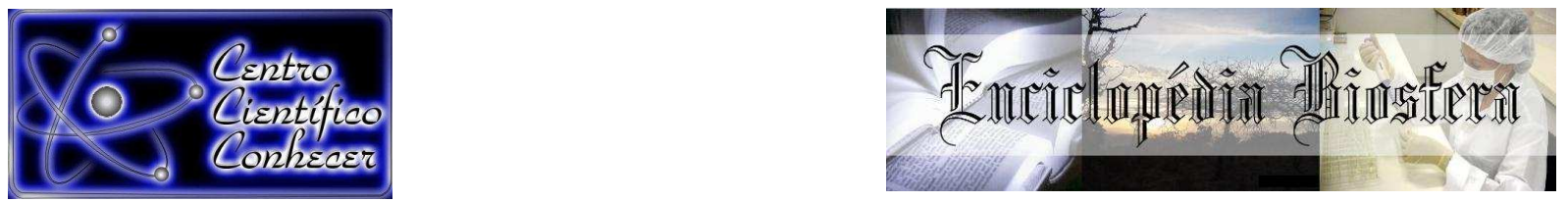

\title{
ANÁLISE DERIVATIVA DE DADOS DE REFLECTÂNCIA OBTIDOS POR ESPECTRORRADIOMETRIA PARA CARACTERIZAÇÃO DE ESPÉCIES ARBÓREAS
}

\author{
Franciel Eduardo Rex ${ }^{1}$, Pâmela Suélen Käfer ${ }^{2}$, Marcos Santos $^{3}$, Elódio Sebem ${ }^{4}$ \\ 1 Graduando do Curso de Engenharia Florestal da Universidade Federal de Santa Maria \\ (francielrexx@hotmail.com), Frederico Westphalen, RS, Brasil \\ 2 Graduando do Curso de Engenharia Florestal da Universidade Federal de Santa Maria \\ 3 Graduando do Curso de Geoprocessamento do Colégio Politécnico da Universidade Federal \\ de Santa Maria \\ 4 Prof. Dr. do Departamento de Ciências Agrárias do Colégio Politécnico da Universidade \\ Federal de Santa Maria
}

Recebido em: 03/10/2016 - Aprovado em: 21/11/2016 - Publicado em: 05/12/2016 DOI: 10.18677/EnciBio_2016B_003

\begin{abstract}
RESUMO
Neste estudo foi utilizada a técnica da análise derivativa, que consiste no realce de feições que se destacam na assinatura espectral de um alvo, para assim identificar variações de reflectância em folhas de espécies florestais. A área escolhida para a coleta do material foi o Jardim Botânico da Universidade Federal de Santa Maria, RS. Foi utilizado um espectrorradiômetro, e a coleta do material procedeu-se através de amostras de três espécies de quatro famílias botânicas, que totalizaram 12 indivíduos. Em cada indivíduo foram feitas 10 leituras em cinco folhas, frente e verso. Os dados foram processados em laboratório no software ASD ViewSpecPro e Microsoft Excel. Como resultado, foram gerados gráficos de assinaturas espectrais por família e um gráfico englobando todas as espécies do estudo. Constatou-se que a análise derivativa demonstrou-se satisfatória, visto que possibilitou a identificação de picos de reflectância que antes não eram visualizados nas curvas espectrais. Os valores máximos de reflectância das espécies, na região da borda vermelha podem ter relação com valores de NDVI.
\end{abstract}

PALAVRAS-CHAVE: Assinatura espectral, Primeira derivada, Sensoriamento remoto.

\section{DERIVATIVE ANALYSIS OF REFLECTANCE DATA OBTAINED BY SPECTRORADIOMETRY FOR FOREST CHARACTERIZATION SPECIES}

\begin{abstract}
In this study we used the technique of derivative analysismm, which consists in the highlight features that stand out in the spectral signature of a target, in order to identify reflectance changes in forest species leaves. The area chosen for the material collection was the Botanical Garden of the Federal University of Santa Maria, RS. A spectroradiometer was used, and the material collection was carried out using samples of three species of four botanical families, totaling 12 individuals. In each individual were made 10 readings in five leaves, front and back. The data were processed in the
\end{abstract}


laboratory in ASD ViewSpec Pro and Microsoft Excel. As a result, we generated graphics spectral signatures per family and a chart encompassing all kinds of study. It was found that the derivative analysis demonstrated to be satisfactory, since it allowed the identification of reflectance peaks that were not displayed in the spectral curves. The maximum reflectance of the species in the red border region, may be related to NDVI values.

KEYWORDS: Spectral signature, First derivative, Remote sensing.

\section{INTRODUÇÃO}

A partir do padrão de assinaturas espectrais das espécies arbóreas, refletidos no comportamento espectral, é possível apontar táticas que possibilitam a permanência no ecossistema (PETCHEY \& GASTON, 2006). Neste contexto, os sensores de campo ou laboratório podem apresentar alta resolução espectral. Assim, os dados obtidos em laboratório ou em campo permitem compreender os princípios químicos e físicos da reflectância dos alvos e são os principais responsáveis pela obtenção dos padrões espectrais dos alvos (BEN-DOR et al., 1999).

Através da espectrorradiometria de reflectância é possível conhecer o comportamento espectral dos alvos na superfície terrestre. Dessa forma, os espectrorradiômetros plotam na forma de gráficos, a intensidade da energia refletida por unidade de comprimento de onda (MENESES, 2012). Essa energia refletida é, por sua vez, representada em forma de gráfico, que é denominado de curva de reflectância espectral. Com a utilização dessa ferramenta, é factível conseguir diversas informações referentes à interação da vegetação com a radiação eletromagnética, e o conhecimento dessa interação possui grande importância para o entendimento dos fenômenos naturais (SILVA et al., 2012), o que possibilita tomar medidas que visam a proteção do ambiente.

Com o objetivo de complementar informações ou ainda de permitir análises mais confiáveis, metodologias estatísticas aliadas as informações de Sensoriamento Remoto formam instrumentos primordiais na busca e no diagnóstico de informações sobre a vegetação, oferecendo estrutura em organizações de atos venturos que auxiliem na conservação e preservação (OTANÁSIO, 2014).

Dentre as técnicas existentes propostas, a análise derivativa tem se mostrado com forte consistência teórica para o uso de informações do Sensoriamento Remoto. Este método consiste no realce de feições que se destacam na assinatura espectral de um alvo, tanto em picos de reflectância como bandas de absorção. A principal vantagem da aplicação da análise derivativa é a possibilidade de produzir dados que sejam menos sensíveis aos componentes que causam variações indesejáveis na radiância detectada por um sensor, a título de exemplo, efeitos causados por mudanças no ângulo solar, cobertura de nuvens, ou pela topografia do local (TSAI \& PHILPOT, 1998), que se comportam como constantes aditivas e espectralmente independentes por toda a extensão do intervalo espectral de interesse.

A aplicação de uma operação de derivada sobre uma função, segundo BARBOSA, (2005), representa um modo de quantificar a taxa de variação de uma determinada variável no que se refere à outra. No caso de um espectro, representa a taxa de variação de reflectância espectral do alvo no que diz respeito à variação do comprimento de onda da energia incidente. No caso da vegetação, através da técnica 
da primeira derivada é factível conseguir resultados relacionados ao vigor, que possui relação direta com o ângulo de inclinação da curva espectral.

Diante do exposto, este trabalho teve como objetivo aplicar a técnica de análise derivativa, na tentativa de identificar os comprimentos de onda que apresentam maior variação de reflectância para as espécies estudadas neste trabalho e, se essa variação possui alguma relação com a família botânica das espécies.

\section{Área de Estudo}

\section{MATERIAL E MÉTODOS}

O local da realização deste trabalho concentrou-se no Jardim Botânico da Universidade Federal de Santa Maria (UFSM) de Santa Maria - RS (Figura 1). A região fisiográfica do município é caracterizada por depressão central do estado do Rio Grande do Sul (Brasil), e fica situado nas coordenadas geográficas 29\%40'31"S e 5354'45"O de Greenwich.

A classificação climática de Köppen classifica o município em uma região de clima do tipo "Cfa", subtropical úmido e a temperatura média anual entre 17,9 e 19,2 ㄷ, sendo a temperatura média do mês mais quente superior a $22^{\circ} \mathrm{C}$. A precipitação média anual varia entre 1.400 e $1.760 \mathrm{~mm}$, sendo bem distribuída ao longo do ano (WREGE et al., 2011).

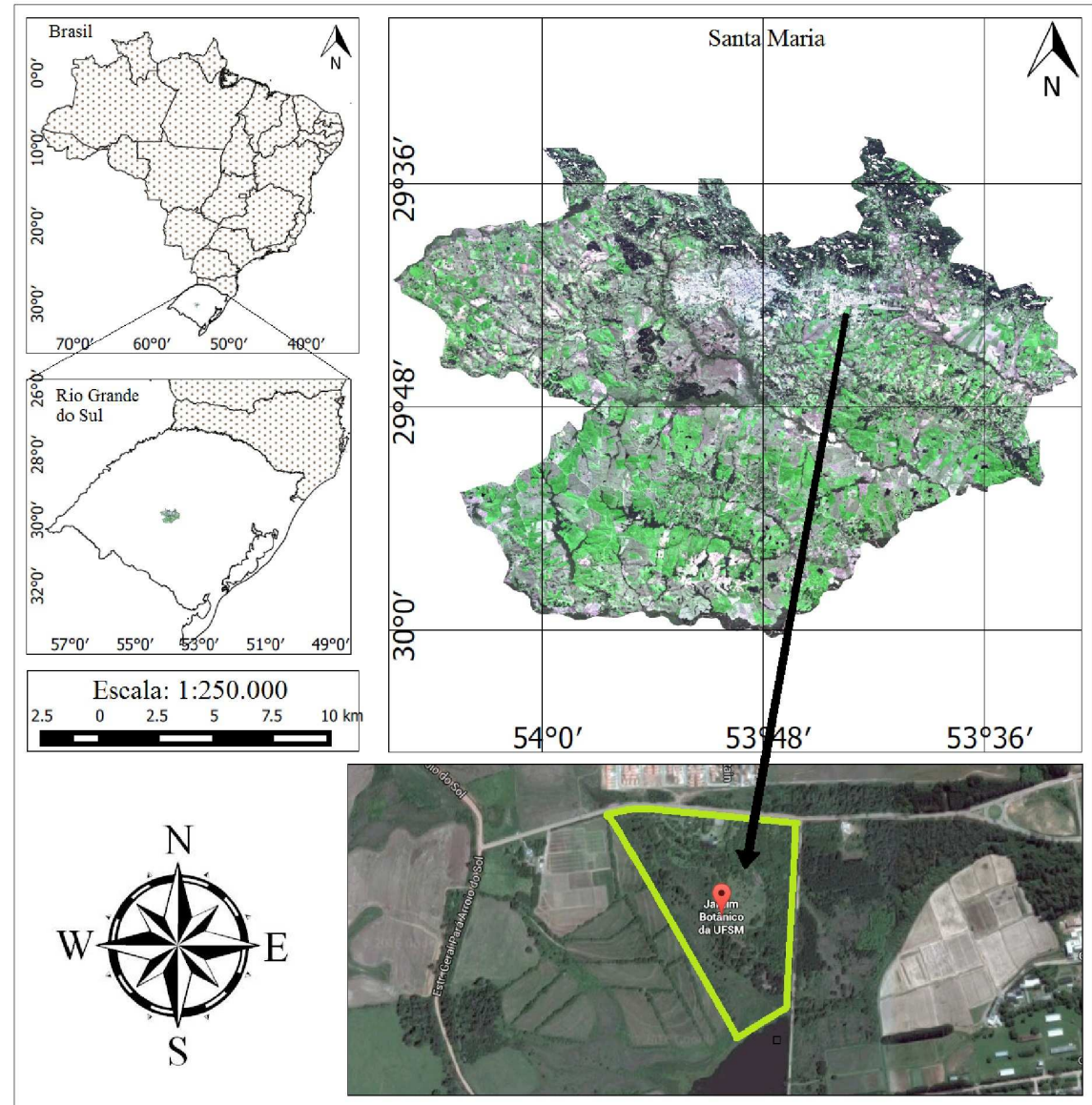

FIGURA 1 Localização da área de estudo. (Adaptado de: USGS, Landsat 8, 2015 e Google Earth; Autoria: KÄFER et al., (2016). 


\section{Caracterização das famílias botânicas}

As espécies utilizadas neste estudo foram as seguintes: Araçá (Psidium cattleianum Sabine), Goiabeira-da-serra (Acca sellowiana (O.Berg) Burret) e a Cerejeira (Eugenia involucrata DC.), estas espécies correspondem a família botânica Myrtaceae. As espécies Pau-Ferro (Caesalpinia leiostachya (Benth.)), Pau-Cigarra (Senna multijuga (Rich.)) e o Rabo-de-mico (Lonchocarpus nitidus (Vogel) Benth) que correspondem à família Fabaceae. As espécies Limoeiro (Citrus limonia Osbeck), Laranjeira (Citrus sinensis L. Osbeck), Bergamoteira (Citrus aurantium L.), correspondem à família Rutaceae. Enquanto as espécies Álamo-Branco (Populus alba L.), Álamo-Negro (Populus nigra L.) e a Guaçantuba (Casearia sylvestris Swartz) dizem respeito à família Salicaceae.

A família Myrtaceae abrange entorno de 5.000 espécies de árvores e arbustos, que se distribuem por todos os continentes, à exceção da Antártida, mas com uma nítida predominância nas regiões tropicais e subtropicais do mundo. Em todos os ecossistemas brasileiros, as Myrtaceae se destacam como uma das famílias mais importantes e diversificadas. As folhas são simples, opostas; venação broquidódroma com nervura intramarginal presente e freqüentemente afastada da margem (AGUIAR, 2013c).

A família Leguminosae ou Fabaceae é a terceira família mais ampla entre as angiospermas, ficando atrás apenas de Orchidaceae e Asteraceae. As folhas geralmente são compostas, porém, pode haver folhas simples, pinadas, bipinadas, trifoliares ou digitadas (AGUIAR, 2013b).

A família Rutaceae possui aproximadamente 1.500 espécies distribuídas pelas regiões tropicais e temperadas do mundo todo, sendo mais abundante na América tropical, sul da África e Austrália. Esta possui folhas basicamente alternas, raramente opostas, simples ou compostas (AGUIAR, 2013d).

A família Salicaceae abrange arbustos ou árvores, raramente lianas, algumas vezes com espinho. De distribuição cosmopolita, inclui cerca de 50 gêneros e 1.000 espécies. No Brasil, ocorrem 10 gêneros e cerca de 80 espécies. Quanto às folhas, apresenta basicamente folhas alternas, simples, com estípulas e geralmente caducas (AGUIAR, 2013a).

\section{Coleta e processamento de dados}

No dia 12 de janeiro de 2016, às 14 horas, foram coletados os dados de reflectância de 12 espécies florestais, de quatro famílias botânicas: Fabaceae, Myrtaceae, Rutaceae e Salicaceae (Tabela 1). Para cada família botânica foram selecionados de forma aleatória três indivíduos (espécies), e em cada indivíduo foram efetuadas 10 medições (repetições) nos lados diferentes da folha de modo a obter espectros representativos das folhas como um todo.

As medidas de reflectância foram obtidas com o Espectrorradiômetro FieldSpec HandHeld 2, aparelho esse que opera na faixa espectral contínua de 325 a 1075 nm, ou seja, desde a região do visível até a do infravermelho próximo e com resolução espectral de $1 \mathrm{~nm}$. Antes de obter as medidas de reflectância o espectrorradiômetro foi otimizado, tendo sido feita a calibração de forma manual.

Os espectrorradiômetros são considerados sistemas sensores remotos nãoimageadores uma vez que detectam a energia eletromagnética (EEM) emitida por uma 
fonte (alvo). Segundo PONZONI \& SCHIMABUKURO, (2012), a forma mais comum para categorizar a EEM, ao longo do espectro eletromagnético, é através do comprimento de onda; sendo o conjunto de radiações a serem detectadas pelo olho humano denominado de espectro visível, compreendido entre $400 \mathrm{~nm}$ e $700 \mathrm{~nm}$, seguido pelo infravermelho próximo, que passa de 1000nm.

Em laboratório, os dados originais foram convertidos para o formato texto (.txt) através do software ASD ViewSpecPro Versão 4.05. e, posteriormente, foi aplicada a técnica da primeira derivada neste mesmo software. Para a obtenção da primeira derivada foi necessário escolher um valor de GAP que se refere a correção das imperfeições. Sendo assim, foi escolhido o valor de número 9, por possibilitar um aparecimento menor de ruídos na curva espectral derivada.

A equação utilizada pelo ASD ViewSpecPro para a aplicação da primeira derivada, segundo o manual do aparelho, foi a seguinte:

$$
F^{\prime}=\frac{[F(+\Delta)-F(-\Delta)]}{2 \Delta}
$$

Onde: $F^{\prime}=$ Primeira Derivada da Reta de Reflectância no ponto F;

$\Delta=$ Distância entre os pontos considerada para o cálculo. Neste estudo foi utilizado um de 9nm de reflectância;

$$
\begin{aligned}
& F(+\Delta)=\text { Valor da Reflectância } \Delta \mathrm{nm} \text { acima do ponto } \mathrm{F} \text { considerado; } \\
& F(-\Delta)=\text { Valor da Reflectância } \Delta \mathrm{nm} \text { abaixo do ponto } \mathrm{F} \text { considerado. }
\end{aligned}
$$

Após o processamento da primeira derivada, os dados foram transferidos para o software aplicativo Microsoft Excel versão 2013, dessa forma, foi possível gerar as curvas espectrais das espécies em estudo, agrupadas por família, e por fim um gráfico geral expondo todas as espécies estudadas.

\section{RESULTADOS E DISCUSSÃO}

Os resultados foram dispostos conforme a geração dos dados. Primeiramente, é apresentado o perfil espectral das espécies da família Myrtaceae, seguido das famílias Fabaceae, Rutaceae e Salicaceae, por fim é apresentado um gráfico contendo todas as espécies deste estudo, a fim de melhor visualizar as diferenças entre as espécies como um todo. De modo geral, as medições apresentaram um ruído bem evidente na faixa de 760nm que segundo MURCRAY (2011) se deve à absorção contínua muito forte nesta região deve-se aos efeitos do aerossol. Ressalta-se que a análise derivativa destaca as maiores variações dos espectros de reflectância, o que permite analisar os componentes dos alvos que alteram suas reflectâncias (MIYOSHI, 2016).

\section{Perfil espectral da família Myrtaceae}

Na Figura 2 são apresentadas as curvas obtidas após a aplicação da primeira derivada, em relação aos dados de reflectância medidos da família Myrtaceae. 


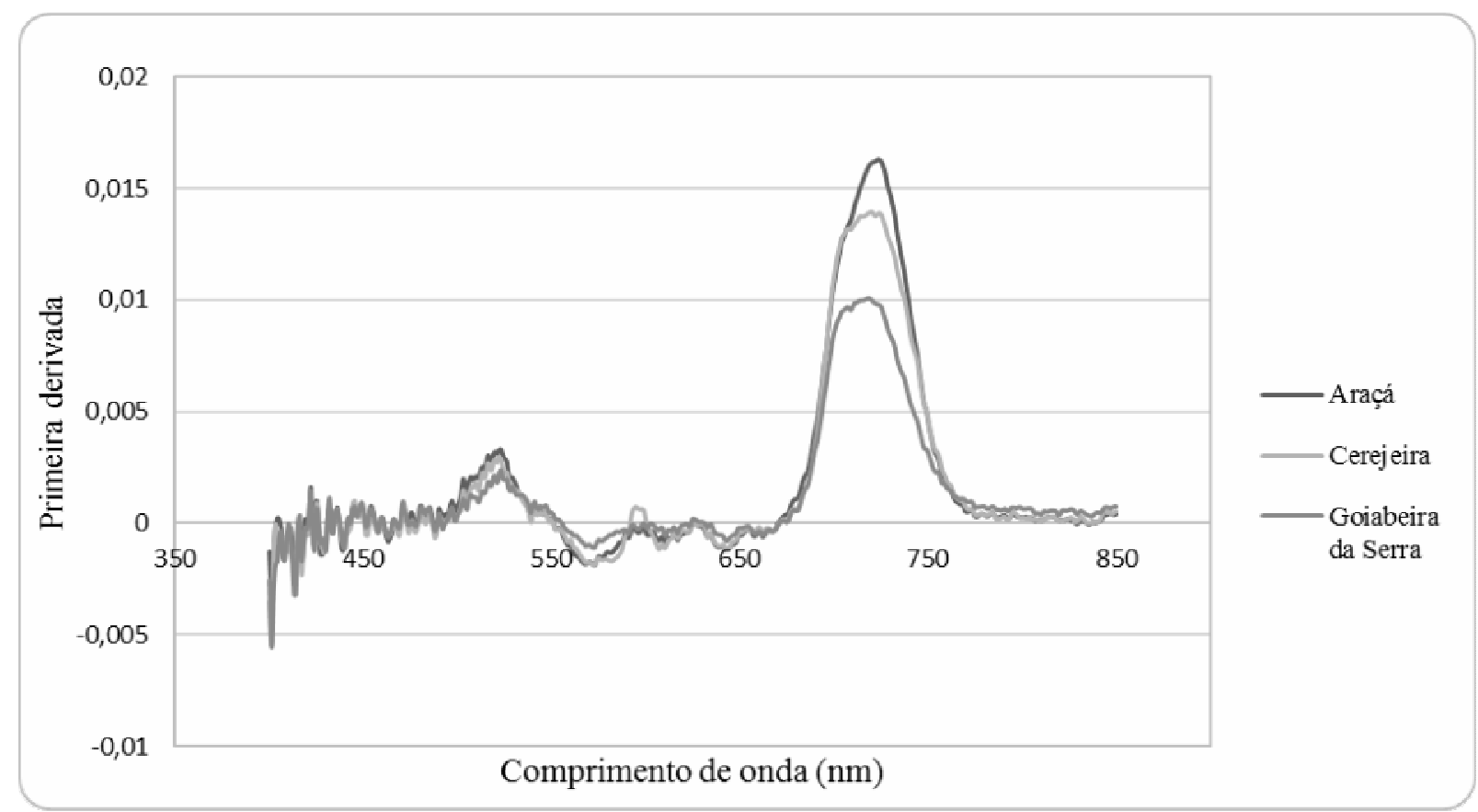

FIGURA 2 Resultado espectral da primeira derivada das espécies da família Myrtaceae. Autoria: REX et al., (2016).

Como pode ser observado na Figura 2, correspondente à primeira derivada da família Myrtaceae, observa-se que a espécie Araçá apresentou um pico de reflectância superior ao das demais espécies da família no intervalo de comprimento de onda de $500 \mathrm{~nm}$ à $550 \mathrm{~nm}$. Esse pico provavelmente ficou mais evidente em função da análise derivativa, já que o estudo anterior realizado por KÄFER et al., (2016), quando estudaram as mesmas famílias botânicas e sem a utilização da técnica, constataram que o Araçá demonstrou a menor reflectância no espectro eletromagnético quando comparado às demais espécies da família Myrtaceae. Embora o pico maior observado tenha sido o da espécie Araçá neste estudo, observou-se ainda que as outras duas espécies da família apresentaram também um pico de reflectância, exibindo assim um comportamento semelhante dessas espécies nesse comprimento de onda. Do mesmo modo, o trabalho anterior de KÄFER et al., (2016) também encontrou um padrão entre as espécies da família no comprimento de onda de $500 \mathrm{~nm}$ à $550 \mathrm{~nm}$.

No comprimento de onda de $600 \mathrm{~nm}$ a curva espectral demonstrou um pico de reflectância para a espécie Cerejeira, diferenciando-a das demais espécies da família que não apresentaram o pico. Esse pico apresentado pela espécie Cerejeira também pode ser atribuído à técnica da análise derivativa, pois novamente com o estudo anterior de KÄFER et al., (2016), não se notam diferenças aparentes da espécie Cerejeira com relação às outras espécies da família, ou seja, esta diferença passa despercebida no espectro eletromagnético e é evidenciada com o uso da primeira derivada. Isso mostra que a técnica é satisfatória para evidenciar diferenças nas curvas espectrais. As espécies: Araçá e Goiabeira-da-Serra apresentaram ainda valores negativos de reflectância, dessa forma, nesse comprimento de onda as espécies da família mostraram-se heterogêneas. 
Até o comprimento de onda de 700 nm as espécies: Araçá e Goiabeira-da-Serra mostraram-se muito semelhantes, posteriormente, na região da borda vermelha, o Araçá foi a espécie que obteve o maior valor de reflectância. A primeira derivada evidenciou essa diferenciação nesse comprimento de onda, visto que esse pico não aparece no trabalho de KÄFER et al., (2016). Assim, o surgimento da maior verticalidade da borda vermelha pode ter relação com o vigor vegetativo, e não é perceptível sem a utilização da análise derivativa, na curva espectral.

Até o comprimento de onda de $700 \mathrm{~nm}$ as espécies Araçá e Goiabeira-da-Serra mostraram-se muito semelhantes, posteriormente, na região da borda vermelha, houve uma maior diferenciação. O Araçá foi a espécie que obteve o maior valor de reflectância. A primeira derivada evidenciou essa diferenciação nesse comprimento de onda, visto que esse pico não aparece no trabalho de KÄFER et al., (2016). O surgimento da maior verticalidade da borda vermelha pode ter relação com o vigor vegetativo (CANAVESI et al., 2010), e não é perceptível sem a utilização da análise derivativa na curva espectral. CASSOL \& GOMEZ (2013) ao estudarem as diferenças entre as espécies Eugenia ramboi e Eugenia rostrifolia encontraram diferenças mais significativas nas suas reflectâncias na região dos infravermelhos próximo e médio, constatando que esta região espectral permite melhor diferenciação destas espécies.

\section{Perfil espectral da família Fabaceae}

A Figura 3 apresenta o perfil espectral das espécies em estudo da família Fabaceae. Quanto ao resultado desta família, as espécies que mais se assemelharam de forma geral foram as espécies Pau-ferro e Pau-cigarra, as quais diferenciaram-se da espécie Rabo-de-mico.

$\mathrm{Na}$ região de 500nm à 550nm a espécie Rabo-de-Mico apresentou o menor pico de reflectância, enquanto que as outras duas espécies estudadas, desta família, apresentaram um resultado muito semelhante nessa região quando comparadas entre si. Essa maior semelhança encontrada entre as espécies Pau-ferro e Pau-cigarra pode ser visualizada apenas com uso da primeira derivada, pois, quando comparada ao estudo anterior realizado por KÄFER et al., (2016), ambas mostraram grandes diferenças na curva espectral.

As diferenças quanto à espécie Rabo-de-mico também foram evidentes na região de 700 à 750nm, onde a espécie Rabo-de-mico apresentou um pico de reflectância maior aproximadamente nos $750 \mathrm{~nm}$, enquanto que as outras duas espécies exibiram o maior pico próximo ao comprimento de onda de $700 \mathrm{~nm}$. Nesse sentido, a maior verticalidade da borda vermelha foi encontrada para a espécie Pau-ferro, dessa forma, podendo significar que as folhas dessa espécie possuíam maior vigor vegetativo. 


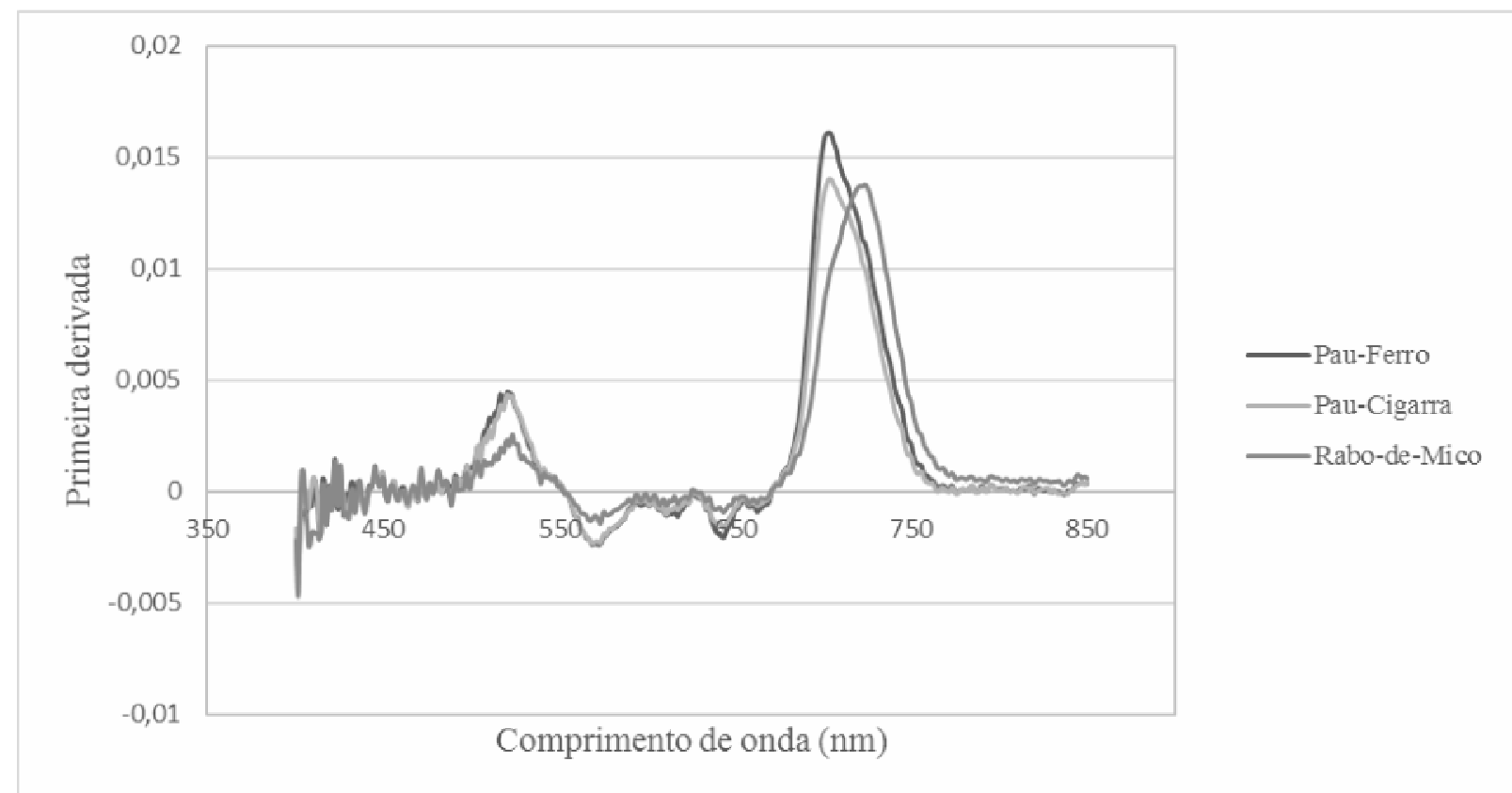

FIGURA 3 Resultado espectral da primeira derivada das espécies da família Fabaceae. Autoria: REX et al., (2016).

Ressalta-se que esses picos ocorridos na borda vermelha (entre 680 e 700nm) são efeitos considerados naturais, já que podem indicar senescência das plantas ou processos de estresse. CARTER \& MILLER, (1994), explicam que os maiores valores de reflectância no comprimento de onda de $700 \mathrm{~nm}$ representaram o que é chamado de "deslocamento da borda vermelha para o azul" (blue shift of the red edge), com referência ao deslocamento do gradiente da transição entre o vermelho e o infravermelho próximo, em direção aos menores comprimentos de onda, o que é perceptível na curva da resposta espectral da vegetação. Em outras palavras, esse resultado pode demonstrar que o intervalo entre 690 e 700nm é particularmente sensível à diminuição precoce do conteúdo de clorofila induzida por estresse e representa o blue-shift da curva de reflectância da borda vermelha que, frequentemente, acompanha o estresse.

\section{Perfil espectral da família Rutaceae}

A Figura 4 apresenta o resultado da primeira derivada em forma de gráfico para a família Rutaceae. A mesma exibiu um comportamento espectral diferente em relação às demais famílias analisadas neste estudo. Na região de $550 \mathrm{~nm}$ à $670 \mathrm{~nm}$ observa-se valores negativos. Assim, em comparação com as outras famílias deste estudo, nota-se que os valores das demais sempre tendem a ser baixos, no entanto, exibem algum pico positivo nessa região. Entretanto, as espécies da família Rutaceae mostraram-se como exceção, já que todas demonstraram valores negativos sem picos e, deste modo, diferenciaram-se das demais famílias deste estudo. KÄFER et al., (2016) ao estudarem as mesmas espécies constataram no espectro eletromagnético que as três espécies demonstraram similar comportamento nesta região do espectro. É importante ressaltar que há necessidade de estudar mais espécies desta família com a aplicação dessa 
técnica, a fim de investigar se outras espécies se comportarão de forma similar ou não, podendo assim ser constatada maior homogeneidade entre a família.

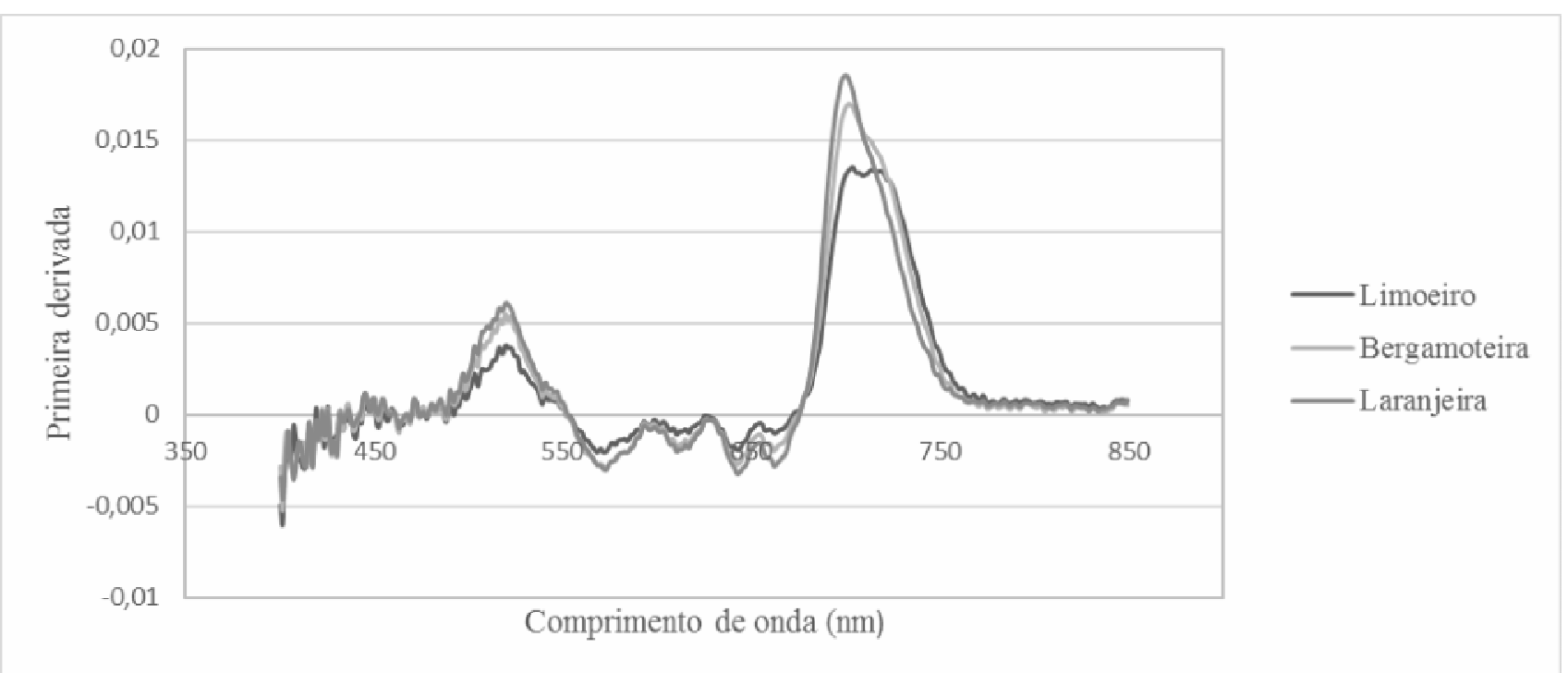

FIGURA 4 Resultado espectral da primeira derivada das espécies da família Rutaceae. Autoria: REX et al., (2016).

Outra região que se revelou diferente para esta família foi a do pico gerado na faixa dos 500nm, onde as espécies Bergamoteira e Laranjeira ultrapassaram 0,05\% de reflectância na primeira derivada, mostrando assim valores superiores aos apresentados pelas outras espécies nessa região do espectro. Esse comportamento seguiu a mesma tendência que o apresentado por KÄFER et al., (2016), onde houve maior similaridade entre as espécies Bergamoteira e Laranjeira, com maiores reflectâncias. Assim, apesar de a primeira derivada não demonstrar resultados diferentes aos apresentados no espectro sem a utilização da técnica, estes se tornaram mais visíveis no espectro. Em geral a espécie Limoeiro apresentou um comportamento espectral caracterizado por baixa reflectância ao longo do espectro em relação às demais espécies desta família, com exceção da faixa que compreende a região de $550 \mathrm{~nm}$ à $670 \mathrm{~nm}$ (região do vermelho), onde apresentou reflectâncias maiores que as outras espécies desta família.

\section{Perfil espectral da família Salicaceae}

A Figura 5 expõe o resultado espectral da primeira derivada para as espécies da família Salicaceae, onde as espécies Álamo Branco e o Álamo Negro demonstraram um comportamento espectral da primeira derivada muito semelhante ao longo do espectro, confirmando assim, que espécies do mesmo gênero provavelmente compartilham as mesmas características que se refletem na assinatura espectral. 


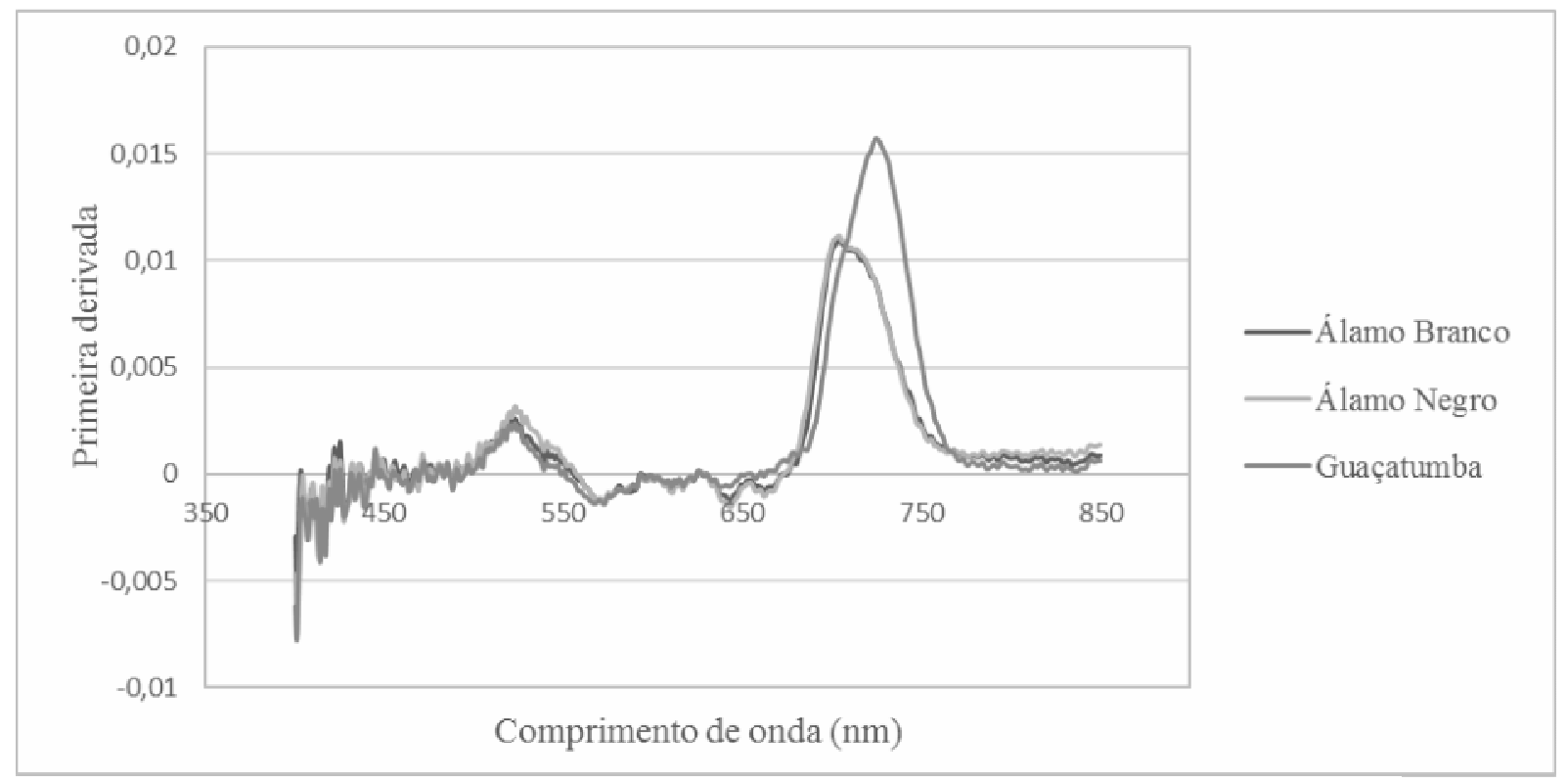

FIGURA 5 Resultado espectral da primeira derivada das espécies da família Salicaceae. Autoria: REX et al., (2016).

A espécie Guaçatumba, demonstrou um comportamento muito semelhante ao das outras até a região de $700 \mathrm{~nm}$. Posteriormente mostrou-se peculiar, já que exibiu uma reflectância muito maior em relação às demais espécies desta família. E possível visualizar que as espécies Álamo Branco e Álamo Negro exibiram curvas praticamente iguais na borda vermelha, demonstrando maior verticalidade do que a curva da espécie Guaçatumba. Como o resultado se repetiu para as duas espécies e ambas pertencem ao mesmo gênero, é possível que esse resultado esteja relacionado com as características deste gênero. No entanto, mais espécies devem ser estudadas a fim de confirmar este resultado.

Perfil espectral de todas as espécies do estudo

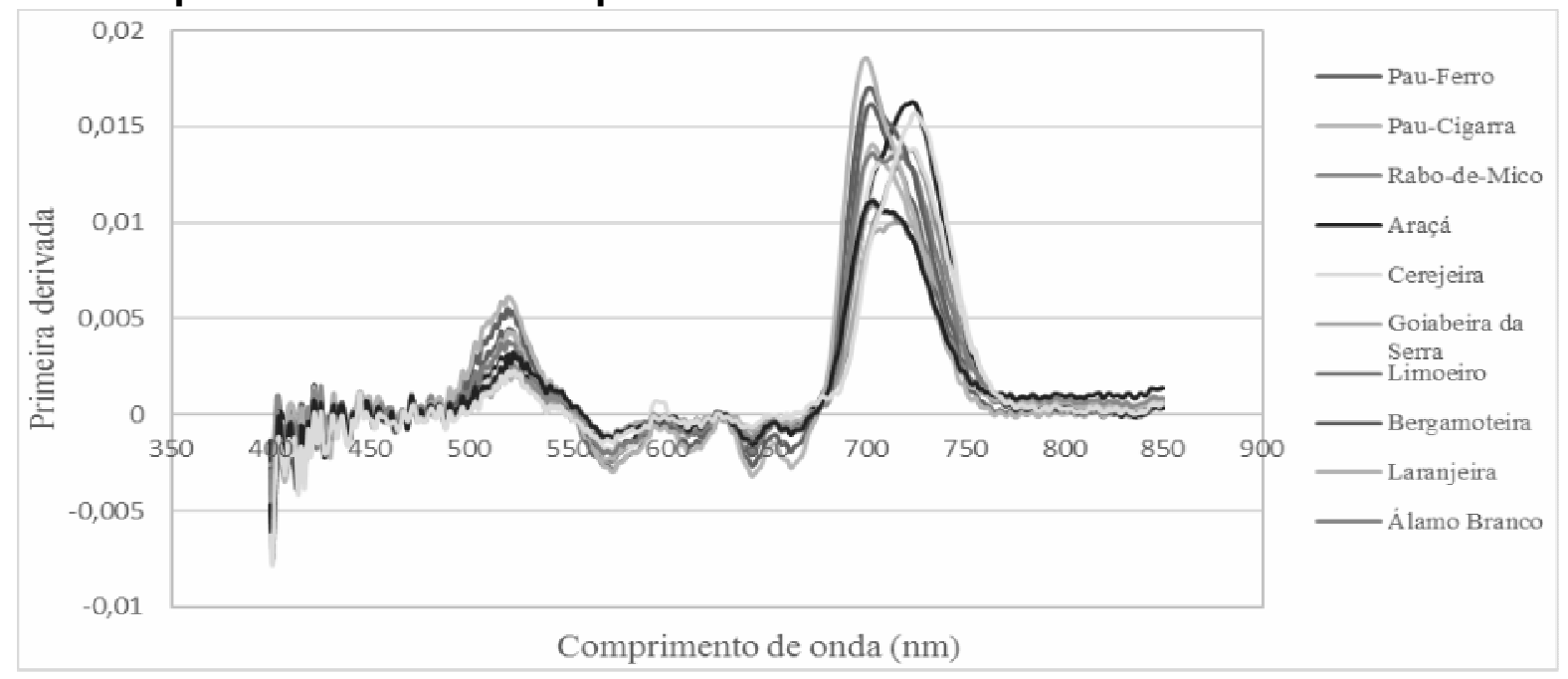

FIGURA 6 Resposta espectral da primeira derivada de todas as espécies estudadas. Autoria: REX et al., (2016).

ENCICLOPÉDIA BIOSFERA, Centro Científico Conhecer - Goiânia, v. 13 n.24; p.35 
De acordo com as assinaturas espectrais das espécies desse estudo, verificouse que a primeira derivada evidenciou algumas diferenças que são visíveis na figura. No intervalo de comprimento de onda de $500 \mathrm{~nm}$ à $550 \mathrm{~nm}$ nota-se que a espécie Laranjeira exibiu o maior pico de reflectância, enquanto que a espécie Goiabeira da Serra exibiu o menor desse comprimento de onda. Já no intervalo de comprimento entre $550 \mathrm{~nm}$ e $600 \mathrm{~nm}$ nota-se que as espécies exibem uma oscilação com a maior amplitude mudando repentinamente de um valor positivo para um valor de reflectância negativo, fato esse que é característico da primeira derivada. A única espécie do estudo que mostrou um pico positivo, diferenciando-se de todas as demais espécies, foi a Cerejeira. Nesse sentido é imprescindível que sejam realizados novos estudos relacionados, principalmente, aos conteúdos das folhas dessas espécies, pois, é possível que exista algum tipo de composto físico ou químico presente nas folhas da espécie que pode ter produzido este comportamento espectral diferenciado.

Em um contexto geral, ao observar a curva espectral, fica claro que a faixa dos $700 \mathrm{~nm}$ até os $750 \mathrm{~nm}$ é onde se encontra a maior diferenciação entre as espécies, já que apresenta os mais variados picos de reflectância. Ao relacionar os máximos valores dos picos das espécies com os valores de NDVI encontrados no estudo de KÄFER et al., (2016), constatou-se que a aplicação da primeira derivada seguiu um mesmo padrão para quase todas as famílias deste trabalho. Para a família Fabaceae, a espécie que apresentou o maior pico de reflectância na região dos 700nm foi a espécie Pauferro, o que pode estar relacionado aos valores de NDVI encontrados no trabalho de KÄFER, et al. (2016), onde a mesma espécie apresentou, também, o maior valor de NDVI.

Para a família Salicaceae, o maior valor de NDVI encontrado no trabalho de KÄFER et al., (2016), foi o da espécie Guaçatumba, essa espécie exibiu o maior pico de reflectância neste estudo. Para a família Myrtaceae, mesma relação foi encontrada. A Cerejeira apresentou o maior valor de NDVI e, também, o maior pico de reflectância entre as espécies da família. Porém para a família Rutaceae, o NDVI do trabalho de KÄFER et al., (2016) não apresentou relações com os resultados dos picos de reflectância da primeira derivada deste estudo. No estudo de KÄFER et al., (2016) a espécie com o maior valor de NDVI foi a Bergamoteira, enquanto que neste estudo o maior pico de reflectância da família foi o da espécie Laranjeia. Mais uma vez ficou evidente a necessidade de realizar novos estudos com mais espécies desta família, para que se possa identificar padrões entre as espécies de uma mesma família.

$\mathrm{Na}$ região do visível, as espécies apresentaram perfil de baixa reflectância, poucas espécies ultrapassaram $0,05 \%$ de reflectância na primeira derivada, apenas as espécies Bergamoteira e Laranjeira demonstraram superiores a essa porcentagem, o que conforme PONZONI \& SHIMABUKURO (2012), pode significar que na região do visível as folhas têm baixa reflectância (menos de $10 \%$ ), devido aos pigmentos existentes nas folhas dominarem a reflectância. Ainda esse resultado é maximizado com a utilização da técnica da primeira derivada, onde a reflectância não passa de $0,05 \%$ na região do visível, nesse estudo. Os pigmentos predominantes absorvem radiação na região azul (próximo a $445 \mathrm{~nm}$ ), mas somente a clorofila absorve na região do vermelho $(670 \mathrm{~nm})$. A maioria das plantas é moderadamente transparente na região do verde $(540 \mathrm{~nm})$. 


\section{CONCLUSÃO}

Ao final deste trabalho, conclui-se que a análise derivativa demonstrou-se satisfatória, pois possibilitou a identificação de picos de reflectância que antes não eram visualizados nas curvas espectrais. Sendo que na família Myrtaceae a espécie Araçá apresentou um pico de reflectância superior ao das demais espécies no comprimento de onda de $500 \mathrm{~nm}$ à $550 \mathrm{~nm}$ e na região da borda vermelha. No comprimento de onda de $600 \mathrm{~nm}$ a espécie Cerejeira destacou-se com um pico de reflectância.

O aparecimento da maior verticalidade da borda vermelha não é perceptível sem a utilização da análise derivativa, e este, pode ter relação com o vigor vegetativo das espécies. Na região de $500 \mathrm{~nm}$ à $550 \mathrm{~nm}$, para a família Fabaceae, as espécies Pauferro e Pau-cigarra apresentaram grande semelhança quando comparadas entre si. Ambas exibiram a maior verticalidade da borda vermelha.

Quanto a família Rutaceae, na região de $550 \mathrm{~nm}$ à $670 \mathrm{~nm}$ as espécies diferenciaram-se das demais famílias do com valores negativos. Há necessidade de estudar mais espécies desta família com a aplicação dessa técnica, a fim de identificar maiores homogeneidades. Devido à escassez de estudos bibliográficos sobre a aplicação da primeira derivada em espécies florestais, indica-se que sejam realizados estudos com mais espécies florestais.

\section{REFERÊNCIAS}

AGUIAR, C. Botânica para ciências agrárias e do ambiente. In: Salicaceae. Bragança: Instituto Politécnico, cap 44, p 58-58, 2013. (a)

AGUIAR, C. Botânica para ciências agrárias e do ambiente. In: Fabaceae. Bragança: Instituto Politécnico, cap 48, p 59-61, 2013. (b)

AGUIAR, C. Botânica para ciências agrárias e do ambiente. In: Myrtaceae. Bragança: Instituto Politécnico, cap 55, p 69-69, 2013. (c)

AGUIAR, C. Botânica para ciências agrárias e do ambiente. In: Rutaceae. Bragança: Instituto Politécnico, cap 66, p 69-69, 2013. (d)

BARBOSA. C. C. F. Sensoriamento remoto da dinâmica da circulação da agua do sistema planície de Curuai/Rio Amazonas. 2005. 255 p. Tese (Doutorado em Sensoriamento Remoto) Instituto Nacional de Pesquisas Espaciais - INPE, São Jose dos Campos. 2005.

BEN-DOR, E., IRONS, J. R., EPEMA, G. F. Soil reflectance. In: RENAZ, A. N. (Ed.). Remote sensing for the Earth Sciences. Manual of remote sensing. 3th ed. [San Francisco]: Wiley, p. 111-188.1999

CARTER, G. A.; MILLER, R. L. Early detection of plant stress by digital imaging within narrow stress-sensitive wavebands. Remote Sensing of Environment, v. 50, p. 295302, 1994. Disponível em: <doi: 10,1016 / 0034-4257 (94) 90079-5>.

CASSOL, H. L. G.; GOMEZ, A. A. Espectrorradiometria como auxílio na diferenciação de espécies com características botânicas muito similares: Eugenia ENCICLOPÉDIA BIOSFERA, Centro Científico Conhecer - Goiânia, v.13 n.24; p.37 2016 
rostrifolia D. Legrand e Eugenia ramboi D. Legrand. Anais XVI Simpósio Brasileiro de Sensoriamento Remoto - SBSR, Foz do Iguaçu, PR, 2013.

KÄFER, P. S.; REX, F. E.; SANTOS, M. A. G.; SEBEM, E. Caracterização espectral e NDVI de espécies florestais das famílias fabaceae, myrtaceae, rutaceae e salicaceae. Enciclopédia Biosfera, v. 13, p. 262-275, 2016. Disponível em: <DOI: 10.18677/Enciclopedia_Biosfera_2016_024>

MENESES, P. R. Princípios de sensoriamento remoto. In.: MENESES, P. R. e ALMEIDA, T. Introdução ao processamento de imagens de sensoriamento remoto. Brasília: UNB, p. 01-33.2012.

MIYOSHI, G. T. Caracterização espectral de espécies da Mata Atlântica de interior em nível foliar e de copa. (Tese de doutorado). Universidade Estadual Paulista, Presidente Prudente, SP, 143p. 2016.

MURCRAY, F. J. BALLOON.01.report. NASA BalloonProgram, 2011. Disponível em: <http://eospso.gsfc.nasa.gov/ftp_docs/validation/Murcray.balloon.01.report.pdf> Acesso em: 20.jan.2015.

OTANÁSIO, P. N. Utilização de dados orbitais para avaliação da integridade das Áreas de Preservação Permanentes (APP) da região administrativa de Planaltina (DF). 2014. 45 f., il. Trabalho de Conclusão de Curso (Bacharelado em Gestão Ambiental) —Universidade de Brasília, Planaltina, 2014.

PONZONI, F. J.; SHIMABUKURO, Y. E; Kuplich, T. M. Sensoriamento Remoto da Vegetação. 2. ed. São Paulo: Oficina de Textos, 2012. v. 1. 176p.

PETCHEY, O. L.; GASTON, K. J. Functional diversity: back to basics and looking forward. Ecology Letter, v. 9, p. 741-758, 2006.

SILVA, E. A.; MARANGON, G. P.; DESSBESELLI, L.; MORAIS, W. W. C.; LIPPET, D. B.; PEREIRA, R.S. Caracterização espectral na reflectância de Eucalyptus grandis Hill ex Maiden. Revista Floresta (Online) (Curitiba), v. 42, p. 285-292, 2012. Disponível em: $<$ http://dx.doi.org/10.5380/rf.v42i2.17587>.

TSAI, F.; PHILPOT W. Derivative Analyses of Hyperspectral Data. Remote sensing Environoment, St. Paul, v. 66, p. 41-51, 1998. Disponível em: <http://dx.doi.org/10.1117/12.262471>. doi: 10,1117 / 12,262471.

WREGE, M.S.; STEINMETZ, S.; REISSER JR, C.; ALMEIDA, I.R. Atlas Climático da Região Sul do Brasil: Estados do Paraná, Santa Catarina e Rio Grande do Sul. Pelotas, RS:, 2011. 336 p. 